\title{
A COMPARISON OF AMETHOCAINE CREAM WITH LIGNOCAINE-PRILOCAINE CREAM (EMLA) FOR REDUCING PAIN DURING RETROBULBAR INJECTION
}

\author{
P. W. JOYCE, P. SUNDERRAJ, J. VILLADA, J. KIRBY and A. WATSON \\ Southport
}

\begin{abstract}
SUMMARY
A prospective, randomised, double-masked, placebocontrolled study was carried out on 169 patients undergoing cataract extraction to compare the topical anaesthetic cream amethocaine with EMLA (eutetic mixture of local anaesthetic, lignocaine and prilocaine) and placebo in reducing pain during retrobulbar injection. Fifty-eight patients received EMLA, 55 amethocaine and 56 the placebo. The pain was assessed objectively by the anaesthetist and subjectively by the patient. Significantly lower pain scores were observed in those patients who had amethocaine $(\boldsymbol{p}<0.001)$ or EMLA $(\boldsymbol{p}<\mathbf{0 . 0 0 5})$ in comparison with those who had placebo, but there was no statistical difference between amethocaine and EMLA $(p>0.1$; $t$-test). No systemic or local side-effects were encountered in any group.
\end{abstract}

Since the introduction of the topical anaesthetic cream EMLA (eutetic mixture of local anaesthetic, lignocaine and prilocaine) into clinical practice, other local anaesthetic agents have been evaluated for topical use. A study comparing a local anaesthetic cream containing amethocaine (Anethaine, Evans) with EMLA found that amethocaine had a rapid onset of action, longer duration of action and provided equally effective analgesia as EMLA.'

With the increasing trend for local anaesthesia in the United Kingdom (retrobulbar, peribulbar or posterior bulbar injections) the need to relieve patient anxiety and pain is important. ${ }^{2}$ Recently it has been shown that EMLA is effective in relieving the pain of needle puncture of the skin at the time of retrobulbar injection. ${ }^{3}$ We wished, therefore, to compare EMLA cream with amethocaine cream in relieving this pain.

\section{PATIENTS AND METHODS}

One hundred and sixty-nine patients between the ages of

Correspondence to: Mr P. W. Joyce, FRCOphth, Department of Ophthalmology, Southport and Formby NHS Trust, District General Hospital, Town Lane, Kew, Southport, Merseyside PR8 6NJ, UK.
52 and 97 years were recruited for the study. Informed, written consent was obtained from all patients. Approval for the study was given by the hospital ethics committee.

The study was a placebo-controlled, double-masked comparison of EMLA with amethocaine cream and placbo. The treatments were distributed at random and at the end of the study 58 patients had received EMLA, 56 placebo and 55 amethocaine. None of the patients received any premedication either orally or intravenously.

EMLA 5\% cream consists of a mixture of lignocaine base $25 \mathrm{mg} / \mathrm{ml}$ and prilocaine base $25 \mathrm{mg} / \mathrm{ml}$. Amethocaine $1 \%$ cream consists of the drug in a non-greasy base. The placebo cream, a mixture of light liquid paraffin, white soft paraffin and wool fat, was visually identical to EMLA and amethocaine.

Approximately $2 \mathrm{ml}$ of cream was applied in the ward by a nurse to the skin of the outer half of the inferior orbital margin at least 1 hour pre-operatively. The cream was covered with a Tegaderm (3M) occlusive dressing. On thepatient's arrival at the anaesthetic room the dressing was removed and the cream wiped off with a dry dressing. Local reactions, if any, were recorded by the doctor administering the retrobulbar injection, who was unaware of the nature of the cream.

Retrobulbar injections were performed with a 23 gauge, $30 \mathrm{~mm}$ long disposable needle. The needle was introduced at the junction of the lateral one-third with the medial two-thirds of the inferior orbital margin. Up to $5 \mathrm{ml}$ of $0.5 \%$ bupivacaine hydrochloride with 1500 units of hyaluronidase were used to achieve effective akinesia. This technique was used for all patients in the study. The doctor who performed the injection was required to make two observations. The first concerned the reactions of the patient at the moment the needle punctured the skin. These were graded on the following scale:

0 (no pain): no reaction to pain.

1 (mild or moderate pain): transient grimace, slight grimace or minor reflex movement. 
2 (severe pain): loud or continuous verbal complaint, intensive or continuous reflex movement.

The second concerned the subjective assessment of the intensity of the pain by the patient. The patients were requested to grade the pain on a scale between 0 (no pain) and 10 (intolerable pain).

The statistical significance of the difference between the patients who received EMLA, amethocaine and placebo creams were analysed by chi-squared $\left(\chi^{2}\right)$ test for the results of the patients' reactions to the retrobulbar injections as assessed by the doctor who gave the injection. The unpaired $t$-test was used for analysing the results of the patient's subjective assessment of pain.

\section{RESULTS}

The results from 169 patients undergoing cataract surgery were analysed. No patient was withdrawn from the study. The characteristics of the three groups of patients are presented in Table I. There were no statistical differences between the three groups in their baseline characteristics.

The patients' responses to the puncture of the skin during retrobulbar injection as observed by the doctor giving the injection are shown in Table II. Treatment with EMLA cream $\left(\chi^{2}=10.6, \mathrm{df}=2, p<0.01\right)$ and with amethocaine cream $\left(\chi^{2}=9.5, \mathrm{df}=2, p<0.01\right)$ resulted in significantly less pain when compared with placebo. However, there was no statistically significant difference

Table I. Patient characteristics

\begin{tabular}{lcccc}
\hline & \multicolumn{3}{c}{ No. of Patients } & \\
\cline { 2 - 4 } Patient group & $\mathrm{M}$ & $\mathrm{F}$ & Total & Age $(\mathrm{yr})^{\mathrm{a}}$ \\
\hline Placebo & 19 & 37 & 56 & $78.5(8.3)$ \\
EMLA & 20 & 38 & 58 & $77.3(7.7)$ \\
Amethocaine & 19 & 36 & 55 & $78.1(7.7)$ \\
\hline
\end{tabular}

${ }^{a}$ Values are the mean (SD).

Table II. The patient response to the retrobulbar injection as observed by the doctor

\begin{tabular}{lcccc}
\hline & \multicolumn{2}{c}{ No. of patients with pain score } & \\
\cline { 2 - 4 } Patient group & 0 & 1 & 2 & $\begin{array}{c}\text { Total no. } \\
\text { of patients }\end{array}$ \\
\hline Placebo & 28 & 19 & 9 & 56 \\
EMLA & 38 & 20 & - & 58 \\
Amethocaine & 37 & 16 & 2 & 55 \\
\hline
\end{tabular}

Table III. Subjective assessment of pain during retrobulbar injection

\begin{tabular}{|c|c|c|c|c|c|c|c|c|c|c|c|}
\hline \multirow{2}{*}{$\begin{array}{l}\text { Patient } \\
\text { group }\end{array}$} & \multicolumn{10}{|c|}{ No. of patients with pain score: } & \multirow{2}{*}{$\begin{array}{l}\text { Total no. } \\
\text { of patients }\end{array}$} \\
\hline & 0 & 1 & 2 & 3 & 4 & 5 & 6 & 7 & 8 & 9 & \\
\hline Placebo & 4 & 8 & 8 & 7 & 5 & 8 & 9 & 3 & 4 & - & 56 \\
\hline EMLA & 4 & 12 & 19 & 13 & 2 & 3 & 4 & 1 & - & - & 58 \\
\hline Amethocaine & 6 & 10 & 14 & 12 & 5 & 3 & 4 & 1 & - & - & 55 \\
\hline
\end{tabular}

between EMLA and amethocaine $\left(\chi^{2}=2.2, \mathrm{df}=2\right.$, $p>0.1$.

The pain at the time of skin puncture during retrobulbar injection as subjectively assessed by the patients is indicated in Table III. Patients who received EMLA cream (mean pain score 2.4, SD 1.6; $t=3.482, p<0.001$ ) and those who received amethocaine cream (mean pain score 2.5 , SD 1.8; $t=3.123, p<0.005$ ) scored significantly less pain compared with those who had received the placebo (mean pain score 3.8, SD 2.4).

No significant local adverse effects were noted and there were no cases of marked erythema, scaling, oedema, or allergic reaction in either the EMLA, amethocaine or placebo groups.

\section{DISCUSSION}

Our study suggests that amethocaine cream is equally effective as EMLA in alleviating the pain associated with needle puncture of the skin during retrobulbar injection. Although the safety of topically applied amethocaine cream has been questioned after several reports of toxic reactions, ${ }^{4-6}$ it has been pointed out that when amethocaine cream is applied to the skin, as opposed to mucous membranes, both the speed and degree of systemic absorption are greatly reduced. ${ }^{7}$ In addition no local or systemic side-effects were encountered in this study. In conclusion, we believe that amethocaine cream is as effective and safe as EMLA in reducing the pain of the skin puncture during retrobulbar injection.

We are grateful for the secretarial assistance of Miss Emma Jones.

Key words: Amethocaine, EMLA, Retrobulbar anaesthesia, Topical anaesthetic cream.

\section{REFERENCES}

1. McCafferty DF, Woolson AD, Boston V. In vivo assessment of percutaneous absorption of local anaesthetic preparation. Br J Anaesthesiol 1989;62:17-21.

2. Hodgins PR, Luff AJ, Morrell AJ, Teye Botchway L, Featherston JJ, Fielder AR. Current practice of cataract extraction and anaesthesia. Br J Ophthalmol 1992;76:323-6.

3. Sunderraj P, Kirby J, Joyce PW, Watson A. A doublemasked evaluation of lignocaine-prilocaine cream (EMLA) used to alleviate the pain of retrobulbar injection. $\mathrm{Br} \mathbf{J}$ Ophthalmol 1991;75:130-2.

4. Jackson CA. Amethocaine hydrochloride: severe toxic effects when used for bronchoscopy. BMJ 1949;1:99-101.

5. Jenkins AV. Acute convulsive reaction to surface anaesthetic: treatment by depolarizing muscle relaxant. $\mathrm{Br} \mathrm{J}$ Anaesthesiol 1962;34:61-4.

6. Bonica JJ. Regional anaesthesia with tetracaine (amethocaine). Anaesthesiology 1950;11:606-22, 716-29.

7. Mazumdar B, Tomlinson AA, Faulder CC. Preliminary study to assay plasma amethocaine concentrations after topical application of a new local anaesthetic cream containing amethocaine. Br J Anaesthesiol 1991;67:432-6. 